\title{
Studies on Curing Process of Epoxy Resins by High-Resolution Pyrolysis-Gas Chromatography
}

\author{
Hiroshi Nakagawa, Sei Wakatsuka, Shin Tsuge, ${ }^{\dagger}$ \\ and Toshiyuki KOYAMA* \\ Department of Chemistry, Faculty of Engineering, Nagoya University, \\ Nagoya 464, Japan \\ * Chemicals Laboratory, Mitsubishi Petrochemical Co., Ltd., \\ Yokkaichi-shi, Mie 510, Japan
}

(Received May 21, 1987)

\begin{abstract}
The curing processes of epoxy resins cured with a dicarboxylic acid anhydride or in the presence of an imidazole catalyst were studied by high-resolution pyrolysis-gas chromatography. The yields of the pyrolyzates with epoxide groups decreased with increase in the degree of curing, while those of various phenols characteristic of prepolymer skeleton increased. Additionally, the yields of low boiling pyrolyzates such as ethylene oxide, propylene, acrolein and acetone also specifically changed with the degree of curing. The obtained results are discussed in comparison with the results from other techniques such as glass transition temperature measurements and FT-IR.

KEY WORDS Pyrolysis-Gas Chromatography / Epoxy Resin / Curing Process /
\end{abstract}

The curing process of epoxy resins has been most often studied by IR from the changes in the spectra due to the change in the chemical structures through the curing process. Klaban et al. ${ }^{1}$ studied curing reactions between an epoxy prepolymer and hexahydrophthalic acid anhydride. It was found that cure reactions were accelerated by alkali halides such as $\mathrm{NaCl}$ and $\mathrm{LiCl}$. Stevens $\mathrm{s}^{2,3}$ assigned the molecular vibrational peaks ranging from 400 to $4000 \mathrm{~cm}^{-1}$ and discussed the cure kinetics of a bisphenol A epoxy resin/dicarboxylic acid anhydride system on the basis of the changes in optical density through the cure reactions. Strecker ${ }^{4}$ studied the curing reaction between an epoxy resin and carboxyl-terminated polybutadiene after the gel point, using IR transmittance and reflection spectrophotometric techniques. Curing processes of epoxy resin systems catalyzed by tertiary amine and imidazole were studied by Saunders et al. ${ }^{5}$ and Farkas et al., ${ }^{6}$ respectively by IR and NMR. More recently, Smith et al. ${ }^{7,8}$ studied the curing process of epoxy resins catalyzed by boron trifluoride monoethylamine $\left(\mathrm{BF}_{3}{ }^{-}\right.$ MEA) by FT-IR and ${ }^{19} \mathrm{~F}$ NMR. They concluded that fluoroboric acid formed from $\mathrm{BF}_{3}-\mathrm{MEA}$ acted effectively as a catalyst.

Differential scanning calorimetry (DSC) also has been extensively used to study the cure reactions of epoxy resin systems. ${ }^{9-11}$ Crane et al. ${ }^{9}$ has evaluated the heat of cure reactions, the kinetic order and the activation energy for an epoxy-phenolic adhesive by DSC, while Barton $^{10}$ has monitored cross-linking reactions of epoxy resins through glass transition temperature $\left(T_{\mathrm{g}}\right)$ measurements by DSC. Horie et al. ${ }^{11}$ also investigated the cure re-

\footnotetext{
† To whom correspondence should be addressed.
} 
actions of epoxy resins with aliphatic diamines by DSC. The heat of the reactions and the rate constants based on the third order kinetics were determined and discussed for the model reactions. The final conversion was also calculated based on the theory of $T_{\mathrm{g}}$ of the crosslinked polymer systems.

On the other hand, pyrolysis-gas chromatography (PyGC) is another technique applied to intractable materials with network structures which are substantially insoluble and often contain many additives. Previously, the thermal degradation behaviour of epoxy resins cured with various curing agents was studied by high-resolution PyGC. ${ }^{12}$ Various phenols characteristic of prepolymer skeletons and pyrolyzates characteristic of curing agents including intact dicarboxylic acid anhydride were observed. Additionally, pyrolyzates with epoxide groups were also observed on the pyrograms of incompletely cured resins, which suggested potential ability of this technique to study the curing process of epoxy resins.

In the present work, the curing processes of epoxy resin samples cured with a dicarboxylic acid anhydride or an imidazole catalyst to various degrees of cure were studied by highresolution PyGC. In both cases, the yields of the pyrolyzates with epoxide groups decreased with increase in the degree of cure, while those of various phenols characteristic of prepolymer skeleton increased. Additionally, the yields of low boiling pyrolyzates such as ethylene oxide, propylene, acrolein, and acetone proved to change with the degree of cure. These results observed by PyGC corresponded well to those deduced from $T_{\mathrm{g}}$ measurements by DSC. The PyGC results are also discussed in comparison with the results obtained by FTIR.

\section{EXPERIMENTAL}

\section{Conditions for PyGC}

A vertical microfurnace-type pyrolyzer (Yanagimoto GP-1018) was directly attached to a gas chromatograph (Yanagimoto G3800) with a high-resolution fused silica capillary column $(0.2 \mathrm{~mm}$ i.d. $\times 25 \mathrm{~m}$ long $)$ coated with immobilized methylphenylsilicone ( $5 \%$ phenyl) supplied from Hewlett Packard. Details of this pyrolyzer were described in a previous report, where the advantages of the microfurnacetype pyrolyzer in handling thermally changeable materials such as epoxy resins were empirically discussed..$^{12}$ The capillary column was used in a temperature programming mode from 50 to $330^{\circ} \mathrm{C}$ at a rate of $4^{\circ} \mathrm{C} \mathrm{min}^{-1}$. The nitrogen carrier gas flow $\left(30 \mathrm{ml} \mathrm{min}^{-1}\right)$ at the pyrolyzer was reduced to $0.4 \mathrm{ml} \mathrm{min}^{-1}$ at the capillary column through a splitter. Additionally, another PyGC system (Shimadzu GC-7A with the pyrolyzer) which could be temperature programmed from $0^{\circ} \mathrm{C} \quad\left(4^{\circ} \mathrm{C}\right.$ $\min ^{-1}$ ) was also used to separate the lower boiling pyrolyzates. In this case, a fused silica capillary column $(0.25 \mathrm{~mm}$ i.d. $\times 50 \mathrm{~m}$ long $)$ coated with immobilized OV-1701 (14\% cyanophenylmethyl-silicone) was used, and the nitrogen carrier gas flow $\left(40 \mathrm{ml} \mathrm{min}^{-1}\right)$ at the

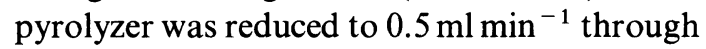
a splitter. In both cases, weighed samples of about $150 \mu \mathrm{g}$ were pyrolyzed at $600^{\circ} \mathrm{C}$.

\section{Conditions for DSC}

The $T_{\mathrm{g}}$ measurements for epoxy resin samples were carried out by DSC using Du Pont Thermal Analyzer 910. Samples of about $1 \mathrm{mg}$ were measured under a nitrogen atmosphere from ambient temperature to about $200^{\circ} \mathrm{C}$ at a rate of $20^{\circ} \mathrm{C} \mathrm{min}^{-1}$.

\section{Conditions for FT-IR}

FT-IR spectra were obtained using Degilab FTS-15C at $4 \mathrm{~cm}^{-1}$ resolution and 500 scans. Samples of about $1 \mathrm{mg}$ were cast into $\mathrm{KBr}$ pellets and measured at ambient temperature under a nitrogen atmosphere. The absorbance of the residual epoxide groups at $910 \mathrm{~cm}^{-1}$ was calculated from the peak height measurement of difference spectra from that of the completely cured sample using benzene $\mathrm{C}-\mathrm{H}$ and 
Table I. Epoxy resin samples with various degrees of cure

\begin{tabular}{|c|c|c|c|}
\hline Samples & $\begin{array}{l}\text { Curing-agent } \\
\text { [composition }{ }^{\mathrm{a}} \text { ] }\end{array}$ & $\begin{array}{c}\text { Accelerator } \\
\text { [composition }{ }^{\mathrm{b}} \text { ] }\end{array}$ & Curing-condition \\
\hline \multicolumn{4}{|c|}{ DGEBA/1B2MZ } \\
\hline A & - & - & - \\
\hline B & - & $\begin{array}{l}\text { 1-Benzyl-2-methyl- } \\
\text { imidazole (1B2MZ) [0.25] }\end{array}$ & $180^{\circ} \mathrm{C}, 3 \mathrm{~h}$ \\
\hline $\mathrm{C}$ & - & $1 \mathrm{~B} 2 \mathrm{MZ}[0.50]$ & $180^{\circ} \mathrm{C}, 3 \mathrm{~h}$ \\
\hline $\mathrm{D}$ & - & $1 \mathrm{~B} 2 \mathrm{MZ}[1.5]$ & $180^{\circ} \mathrm{C}, 3 \mathrm{~h}$ \\
\hline $\mathrm{E}$ & - & $1 \mathrm{~B} 2 \mathrm{MZ}[2.0]$ & $180^{\circ} \mathrm{C}, 3 \mathrm{~h}$ \\
\hline $\mathbf{F}$ & - & $1 \mathrm{~B} 2 \mathrm{MZ}[4.0]$ & $180^{\circ} \mathrm{C}, 3 \mathrm{~h}$ \\
\hline G & - & $1 \mathrm{~B} 2 \mathrm{MZ}[6.0]$ & $180^{\circ} \mathrm{C}, 3 \mathrm{~h}$ \\
\hline $\mathrm{H}$ & - & $1 \mathrm{~B} 2 \mathrm{MZ}[1.5]$ & $180^{\circ} \mathrm{C}, 6 \mathrm{~h}$ \\
\hline \multicolumn{4}{|c|}{ DGEBA/HHPA } \\
\hline I & $\begin{array}{l}\text { Hexahydrophthalic acid } \\
\text { anhydride (HHPA) [80] }\end{array}$ & $\begin{array}{l}\text { Benzyldimethyl- } \\
\text { amine (BDMA) [0.50] }\end{array}$ & - \\
\hline $\mathbf{J}$ & HHPA [80] & BDMA $[0.50]$ & $100^{\circ} \mathrm{C}, 20 \mathrm{~min}$ \\
\hline $\mathrm{K}$ & HHPA [80] & BDMA $[0.50]$ & $100^{\circ} \mathrm{C}, 40 \mathrm{~min}$ \\
\hline $\mathbf{L}$ & HHPA [80] & BDMA $[0.50]$ & $100^{\circ} \mathrm{C}, 1 \mathrm{~h}$ \\
\hline $\mathbf{M}$ & HHPA [80] & BDMA $[0.50]$ & $100^{\circ} \mathrm{C}, 2 \mathrm{~h}$ \\
\hline $\mathrm{N}$ & HHPA [80] & BDMA $[0.50]$ & $100^{\circ} \mathrm{C}, 3 \mathrm{~h}$ \\
\hline o & HHPA [80] & BDMA $[0.50]$ & $100^{\circ} \mathrm{C}, 7 \mathrm{~h}$ \\
\hline
\end{tabular}

a Weight percent per prepolymer.

b $\mu \mathrm{l}$ per $100 \mathrm{mg}$ prepolymer.

$\mathrm{C}-\mathrm{C}$ band as an internal standard. Similarly, absorbance for the ether band at $1040 \mathrm{~cm}^{-1}$ was calculated from the peak height measurement of the difference spectra from that of the uncured sample.

\section{Materials}

Two types of epoxy resin samples with various degrees of cure utilized are listed in Table I together with their curing-conditions and compositions. Diglycidyl ether of bisphenol A (DGEBA, $\bar{M}_{n} \fallingdotseq 340$ ) prepolymer cured at $180^{\circ} \mathrm{C}$ for $3 \mathrm{~h}$ with various amounts of an imidazole catalyst (1-benzyl-2methylimidazole, $1 \mathrm{~B} 2 \mathrm{MZ}$ ) (samples $\mathrm{A}$ to $\mathrm{H}$ ), and DGEBA cured with hexahydrophthalic acid anhydride (HHPA) at $100^{\circ} \mathrm{C}$ for various cure-times (samples I to $\mathrm{O}$ ) were utilized.

\section{RESULTS AND DISCUSSION}

Typical pyrograms of DGEBA cured with various amounts of $1 \mathrm{~B} 2 \mathrm{MZ}$ under the same curing conditions $\left(180^{\circ} \mathrm{C}\right.$ for $\left.3 \mathrm{~h}\right)$ are shown in Figure 1 (samples C, D, and G). Low boiling pyrolyzates and various phenols including bisphenol A characteristic of the prepolymer skeleton were commonly observed on the pyrograms. Among these, intact prepolymer molecules (DGEBA) and monoglycidyl ether of bisphenol A (MGEBA) were markedly observed on the pyrograms of the samples with the lower contents of the catalyst. The DGEBA peak is exclusively due to the thermal volatilization of the original prepolymer remaining in the sample. The MGEBA is formed from the thermal degradation of the intermediate terminals with one unreacted epoxide group as well as from that of the remaining prepolymer. On the other hand, the completely reacted prepolymer moiety mostly yields various phenols characteristic of the prepolymer skeleton although both the remaining prepolymer and the intermediate 


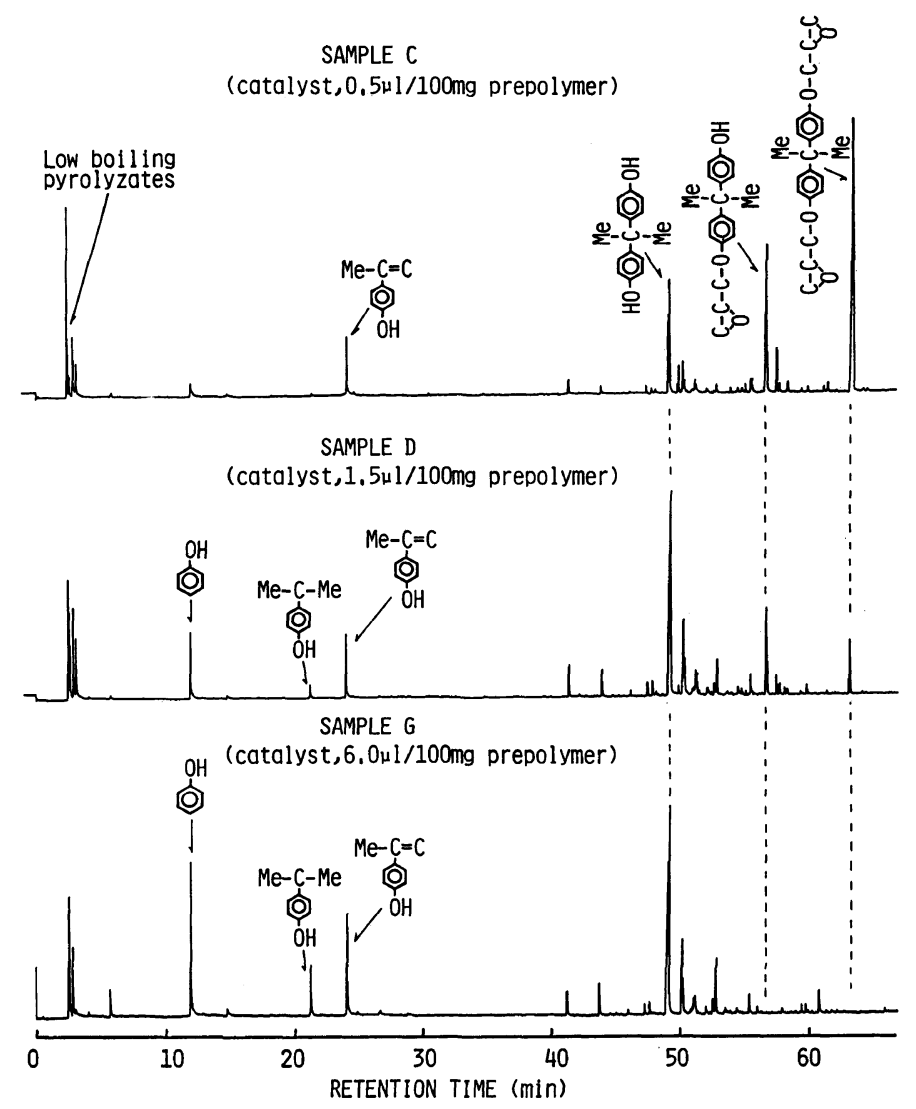

Figure 1. High-resolution pyrograms of epoxy resins cured with various amounts of imidazole catalyst at $180^{\circ} \mathrm{C}$ for $3 \mathrm{~h}$.

terminals also yield the various phenols through pyrolysis to some extent.

Relationships between the observed peak intensities of the characteristic products and the amounts of the catalyst added to a given amount $(100 \mathrm{mg})$ of prepolymer are shown in Figure 2. In this case, peak intensity is defined as the observed peak area normalized by the sample amount $(\mu \mathrm{g})$. The peak intensities of DGEBA and MGEBA decrease with increase in the amount of catalyst which corresponds to the degree of cure. As might be expected, the diepoxide compound (DGEBA) decreased more rapidly than the monoepoxide one (MGEBA) with increase of the catalyst content. On the other hand, peak intensity of bisphenol $\mathrm{A}$ increases with the degree of cure and becomes almost constant after the amount of catalyst exceeds $2 \mu \mathrm{l}$ per $100 \mathrm{mg}$ prepolymer. Under the given cure-conditions, the curing reactions are completed when the amount of the catalyst per $100 \mathrm{mg}$ prepolymer exceeds $4 \mu \mathrm{l}$, where the products with epoxide groups completely disappear on the pyrogram.

Typical pyrograms of DGEBA cured with HHPA at $100^{\circ} \mathrm{C}$ for various cure-times (samples I, K, and O) are shown in Figure 3. In addition to the low boiling pyrolyzates, bisphenol A, and the pyrolyzates with one or two epoxide groups, the peak of intact HHPA molecule was commonly observed on the pyrograms. Also in this case, the peak intensities of the characteristic pyrolyzates change as a function of cure-time. 


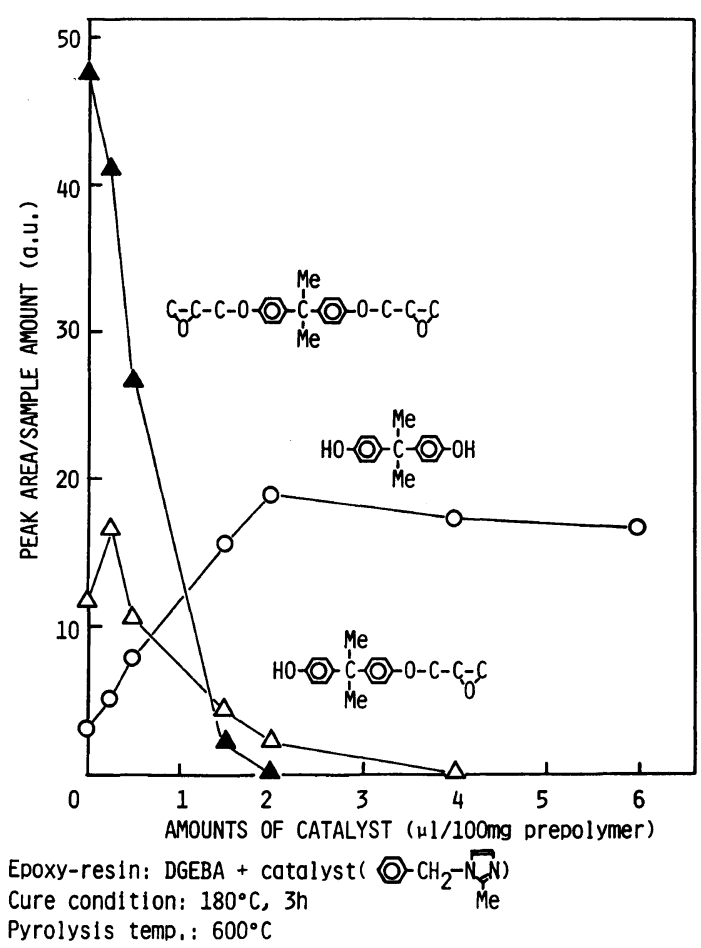

Figure 2. Changes of characteristic products from epoxy resins as a function of catalyst-amount.

Relationships between the peak intensities of the characteristic pyrolyzates and cure-time are shown in Figure 4. Similar to the samples cured with the imidazole catalyst, the peak intensities of the pyrolyzates with epoxide groups decrease with increase in cure-time, while those of bisphenol A increase. However, the fact that MGEBA is still observed on the pyrogram of the sample over-cured up to $7 \mathrm{~h}$ suggests that a small amount of epoxide groups remains unreacted in this system even after the cure is completed. On the other hand, the peak intensity of HHPA slightly decreases in the first stage of cure but remains constant at extended cure-time. This suggests that volatilization of HHPA occurs to some extent competitively in the early stage of the curing process while the reacted HHPA monomer is not completely recovered as the original molecule on the pyrogram through pyrolysis. The fact that the peak intensities of the characteris- tic products become almost constant after $3 \mathrm{~h}$ of cure-time indicates that the cure reactions are completed by about $3 \mathrm{~h}$ at the curetemperature of $100^{\circ} \mathrm{C}$, which agrees well with the cure-conditions recommended by the supplier.

Typical pyrograms in the low boiling-point region are shown in Figure 5 for the two resin systems. The characteristic pyrolyzates of ethylene oxide, propylene, acrolein, acetone, and allyl alcohol are commonly observed on the pyrograms. Furthermore, toluene characteristic of the imidazole catalyst (1B2MZ) is observed on the pyrograms of the resin samples cured with $1 \mathrm{~B} 2 \mathrm{MZ}$, which increases with rise in the amounts of $1 \mathrm{~B} 2 \mathrm{MZ}$ contained in the samples. On the other hand, cyclohexene characteristic of HHPA and benzene characteristic of benzyldimethylamine used as a catalyst are observed on the pyrograms of the resin samples cured with HHPA.

Changes of the low boiling products are shown as a function of the degree of cure in Figures 6 and 7 for the samples cured with $1 \mathrm{~B} 2 \mathrm{MZ}$ and HHPA, respectively. In both resin systems, the peak intensity of ethylene oxide decreases as the degree of cure increases, while those of propylene and acetone increase. These phenomena suggest that propylene and acetone are likely formed from the reacted epoxide groups, while ethylene oxide from the unreacted epoxide groups.

On the other hand, it is interesting to note that the peak intensity of acrolein increases with rise in the degree of cure for the HHPAcured samples, while the opposite tendency is observed for the 1B2MZ-cured samples. This phenomenon suggests that acrolein is likely formed from the reacted epoxide groups with acid anhydride through ester linkages as shown below,

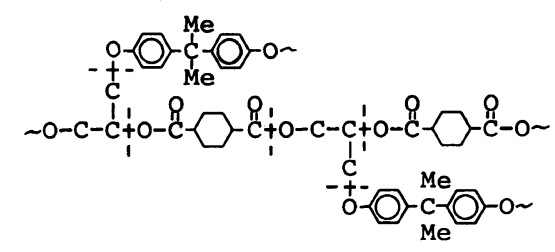




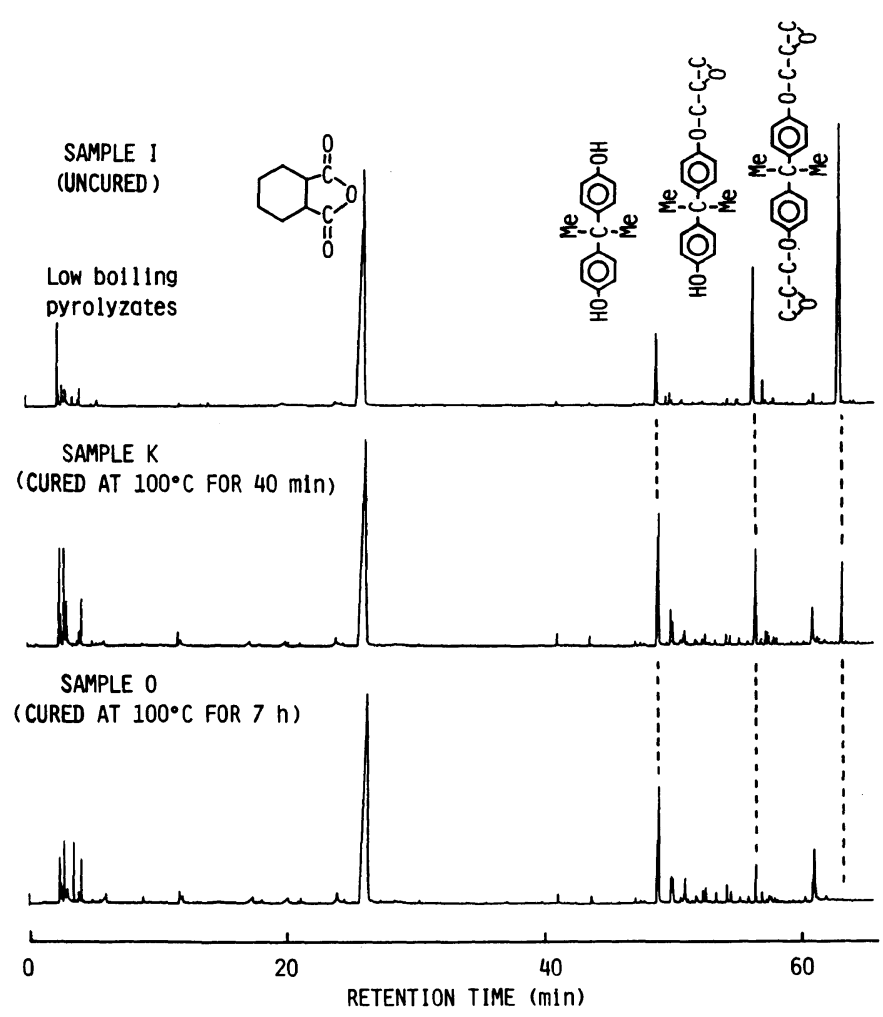

Figure 3. High-resolution pyrograms of epoxy resins cured with HHPA at $100^{\circ} \mathrm{C}$ for various cure-time.

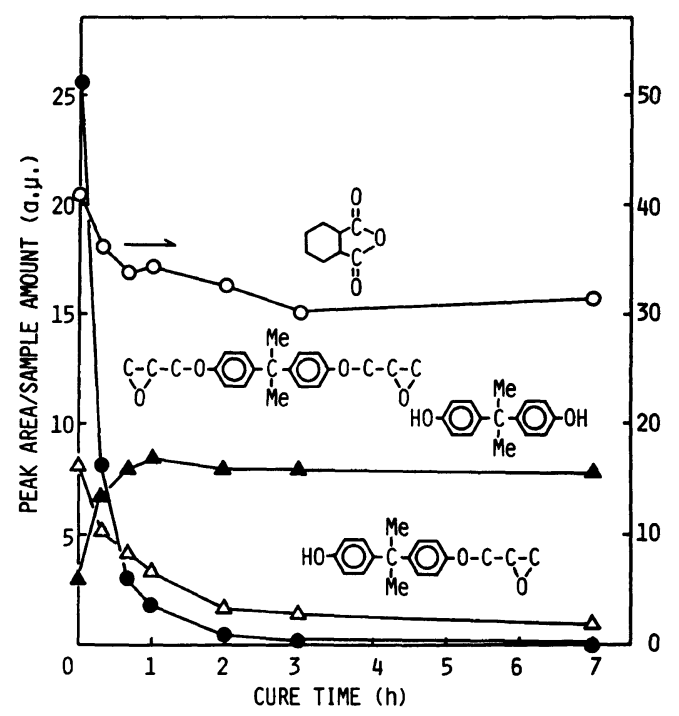

Epoxy-resin: DGEBA + HHPA (5:4), Cure-Temp.:: $100^{\circ} \mathrm{C}$

Figure 4. Changes of characteristic products from epoxy resin as a function of cure-time. while it is scarcely formed from the homopolymerized epoxide groups through the ether linkage as shown below.

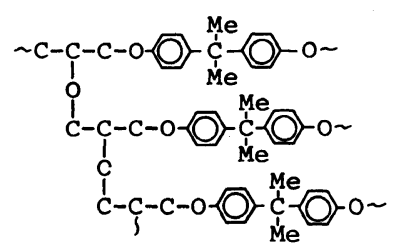

The fact that HHPA is almost quantitatively recovered on the pyrogram suggests that the preferential scission at the $\mathrm{C}-\mathrm{O}$ bonds in the ester linkages to yield HHPA, in turn, might be responsible for the acrolein formation from the cured epoxy resin with ester linkages. Furthermore, the peak intensities of these low boiling pyrolyzates become almost constant at the region where the peak intensities shown in Figures 2 and 4 for the corresponding resin 


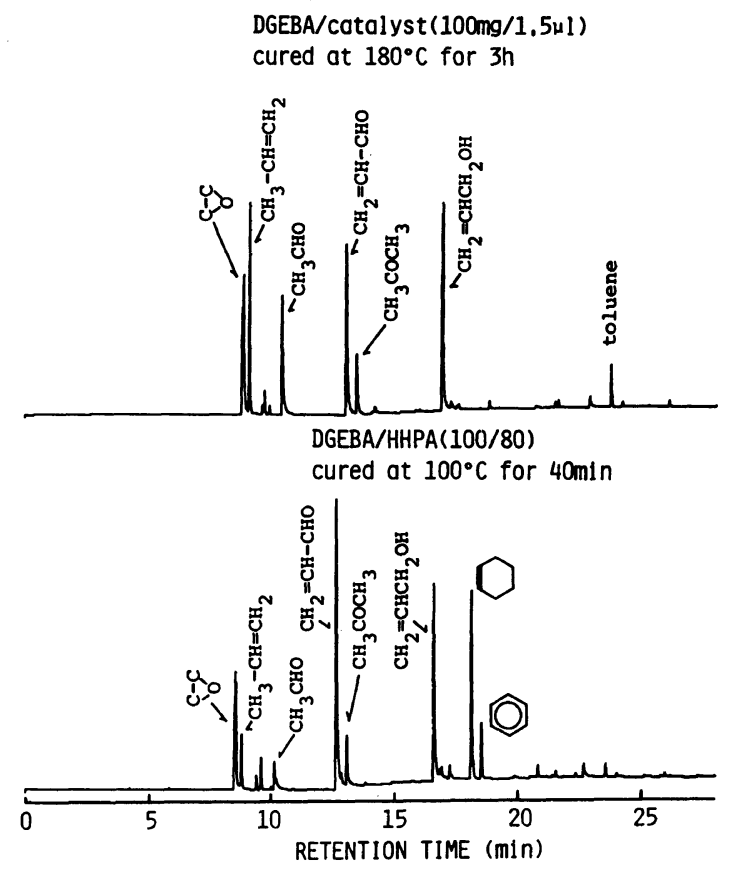

Figure 5. Pyrograms in the low boiling-point region for epoxy resin samples.

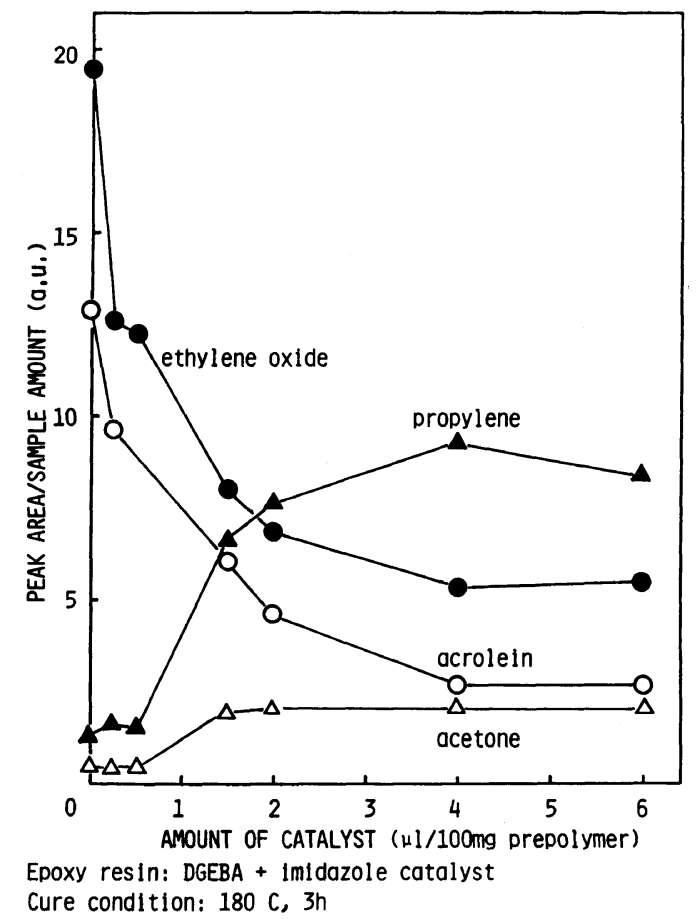

Figure 6. Change of low boiling products as a function of catalyst amount.

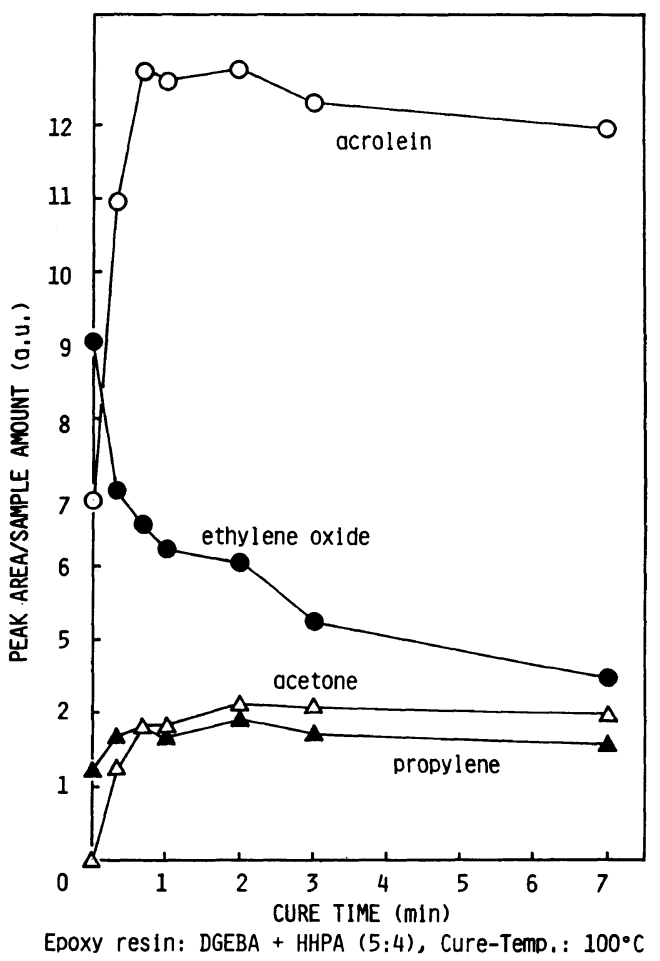

Figure 7. Change of low boiling products as a function of cure-time.

systems become constant.

Comparative results of PyGC, $T_{\mathrm{g}}$ measurements by DSC and FT-IR obtained for representative samples are shown in Table II. The unreacted amounts of epoxide groups ( $\%)$ observed by PyGC are defined by adding the peak intensity of DGEBA and $1 / 2$ of the peak intensity of MGEBA when the values for the uncured samples (samples $\mathrm{A}$ and I) are regarded as $100 \%$. In both resin systems, the residual amounts of epoxide groups observed by PyGC correspond well to $T_{\mathrm{g}}$ values by DSC which are conventionally used to evaluate the degrees of cure. ${ }^{1,11}$

Also in the case of the resin samples cured with imidazole catalyst, the relative amounts of epoxide groups measured by PyGC decrease monotonously with decrease in the corresponding amounts obtained by FT-IR, while those of ether group formed through homopo- 
Table II. Comparative results of PyGC, DSC, and FT-IR for epoxy resin samples

\begin{tabular}{|c|c|c|c|c|}
\hline \multirow[b]{2}{*}{ Samples } & \multirow[b]{2}{*}{$\begin{array}{l}\text { Relative amount of } \\
\text { C-C (\%) by PyGC } \\
\text { O' }\end{array}$} & \multirow{2}{*}{$\begin{array}{c}T_{\mathrm{g}}\left({ }^{\circ} \mathrm{C}\right) \\
\text { by DSC }\end{array}$} & \multicolumn{2}{|c|}{ FT-IR absorbance ${ }^{b}$} \\
\hline & & & $\underset{\mathrm{O}}{\mathrm{C}-\mathrm{C}}\left(\mathbf{C}\left(910 \mathrm{~cm}^{-1}\right)\right.$ & $\mathrm{C}-\mathrm{O}-\mathrm{C}\left(1040 \mathrm{~cm}^{-1}\right)$ \\
\hline \multicolumn{5}{|c|}{ DGEBA/1B2MZ } \\
\hline A & 100 & - & 100 & 0 \\
\hline D & 8.1 & 33.1 & 55.1 & 50.0 \\
\hline $\mathrm{E}$ & 2.1 & 58.1 & 25.8 & 96.0 \\
\hline G & 0 & 99.2 & 0 & 100 \\
\hline $\mathrm{H}$ & 3.7 & 51.7 & 29.2 & 84.0 \\
\hline \multicolumn{5}{|c|}{ DGEBA/HHPA } \\
\hline I & 100 & - & - & - \\
\hline $\mathrm{K}$ & 16.6 & 47.4 & - & - \\
\hline $\mathrm{L}$ & 11.6 & 59.2 & - & - \\
\hline$M$ & 3.7 & 89.4 & - & - \\
\hline $\mathrm{O}$ & 1.6 & 104 & - & - \\
\hline
\end{tabular}

a The values for samples $\mathrm{A}$ and $\mathrm{I}$ is regarded as $100 \%$ for both the DGEBA/1B2MZ and DGEBA/HHPA systems.

b Absorbance for samples $\mathrm{A}$ and $\mathrm{G}$ is regarded as $100 \%$ for both the epoxide and ether bands.

lymerization of the epoxide groups increase. However, the fact that decrements in epoxide groups measured by PyGC are much greater than those observed by FT-IR suggests that the recovery rate of residual epoxide groups as MGEBA from the intermediate terminals with one unreacted epoxide group might be fairly lower than that from DGEBA under given pyrolysis conditions.

In conclusion, the PyGC technique has proved to be a rapid and convenient method for characterizing the cure process of epoxy resins. This technique is also expected to offer a method to analyze the distributions of cure in various practical bulk samples, since a very small amount of sample is enough for PyGC measurements.

Acknowledgment. The authors would like to thank Mitsubishi Petrochemical Co., Ltd. for permission to publish these data. The authors also would like to thank T. Usami and Y. Koma (Mitsubishi Petrochemical Co., Ltd.) for the FT-IR measurements and helpful discussion. This research was financially sup- ported by a Grant-in-Aid for Scientific Research from the Ministry of Education, Science, and Culture of Japan.

\section{REFERENCES}

1. V. J. Klaban, J. Smrčka, and J. Mleziva, Macromol. Chem., 111, 1 (1968).

2. G. C. Stevens, J. Appl. Polym. Sci., 26, 4259 (1981).

3. G. C. Stevens, J. Appl. Polym. Sci., 26, 4279 (1981).

4. R. A. H. Strecker, J. Appl. Polym. Sci., 13, 2439 (1969).

5. T. F. Saunders, M. F. Levy, and J. F. Serino, J. Polym. Sci., A-1, 5, 1609 (1967).

6. A. Farkas and P. F. Strohm, J. Appl. Polym. Sci., 12, 159 (1968).

7. R. E. Smith, F. N. Larsen, and C. L. Long, J. Appl. Polym. Sci., 29, 3697 (1984).

8. R. E. Smith, F. N. Larsen, and C. L. Long, J. Appl. Polym. Sci., 29, 3713 (1984).

9. L. W. Crane, P. J. Dynes, and D. H. Kaelble, J. Polym. Sci., Polym. Lett. Ed., 11, 533 (1973).

10. J. M. Barton, J. Macromol. Sci., Chem., A8, 25 (1974).

11. K. Horie, H. Hiura, M. Sawada, and H. Kambe, $J$. Polym. Sci., A-1, 8, 1357 (1970).

12. H. Nakagawa, T. Koyama, and S. Tsuge, J. Anal. Appl. Pyrol., 12, 97 (1987). 